\title{
O texto visual no livro didático de língua portuguesa: reflexões e desafios em multimodalidade ${ }^{1}$
}

\author{
Rafael Seixas de Amoêdo²
}

Neiva Maria Machado Soares ${ }^{3}$

\begin{abstract}
Resumo
Desde a formulação dos PCN (BRASIL, 1998) até a BNCC (BRASIL, 2016), o ensino de línguas está em constante transformação. A linguagem até então apresentada apenas na modalidade verbal, passa a agregar multissemioses, como o visual, as cores, o design, o som, entre outras, produzindo-se assim textos multimodais. Este trabalho visa analisar como o texto visual está sendo empregado em livros didáticos da coletânea Português Linguagens (CEREJA e MAGALHÃES, 2015), com ênfase na edição do 6o ano, se em natureza meramente ilustrativa ou se estimula ao letramento visual/ multimodal, sob a ótica da Teoria Semiótica Social da Multimodalidade e a Gramática do Design Visual, de Kress e van Leeuwen (1996). A análise de cunho quanti-qualitativo revelou o uso de ilustrações, tendo as imagens função meramente acessória na arquitetura textual-discursiva. Verificando que o livro didático, uma importante ferramenta nas aulas de Língua Portuguesa, pode ser instrumento propício às práticas de multiletramento, mas que na estrutura atual ainda necessita de modificações quanto ao tratamento das imagens, pois estas traduzem valores, conduzem olhares e filtram óticas particulares de perceber o mundo. Utilizá-las apenas de modo subserviente, deturpam além de critérios de coesão e coerência, as perspectivas de multimodalidade, letramento visual e multiletramentos, importantes no contexto escolar contemporâneo.
\end{abstract}

Palavras-chave: Livro Didático; Multimodalidade. Multiletramento.

\section{The visual text in the textbook of portuguese language: reflections and challenges in multimodality}

\begin{abstract}
From the policy formulation of Curriculum Parameters (1998) to the BNCC (BRASIL, 2016), the language teaching are continuously changing. The language previously analyzed only in the biases of verbal modalities, starts to aggregate several semioses, such as visual, colors, design, sound, among others producing multimodal texts. This paper aims to analyze how the visual text is being used in textbooks of the collection Portuguese Language (2015), with emphasis on the edition of the 6th year, if in nature merely illustrative or stimulates visual / multimodal literacy, from the perspective of Social Semiotic Theory of Multimodality (TSSM) and the Grammar of Visual Design (GDV), by Kress and van Leeuwen (2006 [1996]); Kress (2010). The quantitative-qualitative analysis revealed a significant use of illustrations, preponderating to images with a merely accessory function to the sense of the textual-discursive architecture. Noting that the textbook, an important handbook in Portuguese language classes, can be an instrument conducive to multiliteracies practices, but that in the current structure still needs modifications, especially in the treatment of images, since they translate values, filter particular optics to see the world. Using them only subserviently, often without any link to the text, misrepresent beyond cohesion and coherence criteria, the perspectives of multimodality, visual literacy and multiliteracies, important in the contemporary school context.

Keywords: Textbook; Multimodality; Multiliteracy.

\footnotetext{
1 Texto produzido no Programa de Iniciação Científica 2017/2018 da Universidade do Estado do Amazonas e financiado pela Fundação de Amparo à Pesquisa no Amazonas (FAPEAM)

${ }^{2}$ Mestrando do Programa de Pós-Graduação Interdisciplinar em Ciências Humanas (PPGICH) - Universidade do Estado do Amazonas (UEA), Manaus-AM, e-mail: rsda.let@uea.edu.br

${ }^{3}$ Professora adjunta da Universidade do Estado do Amazonas (UEA), Manaus-AM, e-mail: nemsoa@hotmail.com
}

Periódico Horizontes - USF - Itatiba, SP - Brasil - e020007 


\section{Considerações Iniciais}

$\mathrm{Na}$ sociedade contemporânea fluida, termo proposto por Bauman (2007, p.7), a linguagem está deixando de construir significado expresso apenas pelo modo verbal (oral ou escrito) e passa a agregar imagens, cores, recursos visuais, movimentos, entre outros (KRESS, van LEEUWEN, 1996, p.1), constituindo assim um texto multimodal ou multissemiótico. O Livro Didático $(L D)^{4}$, como parte de uma esfera social escolar, também figura nessas transformações. Inicialmente, monocromáticos e com ênfase no texto escrito, hoje há uma infinidade de imagens, cores e recursos gráficos a serviço do processo de ensino-aprendizagem. Também está envolto de certo "preconceito", considerado até um material marginalizado ou como produção menor, passou a ter lugar no escopo de análises em várias perspectivas, observando-se então, como um importante instrumento comunicativo e de transmissão do conhecimento (MAROUN, 2006, p.11).

Nas novas paisagens contemporâneas, contudo, torna-se necessário repensar sobre a importância da função da imagem e de outros recursos semióticos para a construção do todo textual (SOARES, VIEIRA, 2013, p.255). É inegável a importância da composição verbal, mas também se deve destacar quanto aos aspectos imagéticos que dialogam e perfazem a unidade comunicativa e semântica, modos semióticos que dimensionam valores, conduzem olhares e filtram óticas particulares de perceber o mundo.

Neste escopo, este trabalho visa analisar como a multimodalidade está sendo empregada nos livros didáticos da coletânea Português Linguagens do Ensino Fundamental II, dos autores William Cereja e Thereza Magalhães (2015), com ênfase na edição do 6o ano. E se justifica, dada à frequência com que os LD desses autores são utilizados, principalmente na rede pública de ensino em Manaus/Amazonas. Estes materiais propõem "direcionamentos" aos elementos que constituem determinada disciplina, definindo-as. Ressalta-se que identificar a presença (ou ausência) de textos multimodais no livro didático de Língua Portuguesa no Ensino Fundamental II despertou grande interesse em empreender pesquisa sobre o assunto,

\footnotetext{
${ }^{4}$ Neste trabalho utilizar-se-á das nomenclaturas LD para referir-se aos livros didáticos de modo geral e LDP para referir-se aos livros didáticos específicos de Língua Portuguesa, objetos desta pesquisa.
}

Periódico Horizontes - USF - Itatiba, SP - Brasil - e020007 
objetivando analisá-los sob a ótica da Teoria Semiótica Social da Multimodalidade (TSSM), via categorias da Gramática do Design Visual (GDV) de Kress e van Leeuwen (2006 [1996]) quanto ao significado representacional, interacional e composicional.

Inicialmente, é importante investigar brevemente a história e funcionalidade do livro didático (LD) e do livro didático de Língua Portuguesa (LDP).

\section{Breve histórico do livro didático (LD)}

Os livros didáticos utilizados na rede pública de ensino no Brasil são selecionados pelo Programa Nacional do Livro Didático (PNLD) (BRASIL, 2016), um programa do Governo Federal que norteia a escolha dos livros didáticos para um período de três anos subsequentes. É elaborado um guia que reúne diversas obras e composto por informações dos documentos oficiais que regem a educação no Brasil, bem como resenhas e outras informações para os professores e especialistas que farão parte da seleção desses materiais possam selecionar os considerados mais apropriados ao uso.

Contudo, ainda que se tenha "políticas de seleção e diretrizes", ainda carece-se de políticas eficazes relacionadas à produção, divulgação e distribuição de livros didáticos. Entre as celeumas, por exemplo, tem-se o descarte de LD em galpões de reciclagem, conforme noticiado no portal Gaucha $\mathrm{ZH}^{5}$, em dezembro de 2019. Livros que deveriam ser utilizados pelas escolas, pois ainda estavam em "prazo de validade" até 2022 e revela uma falha no sistema de remanejamento dos livros pelo Ministério da Educação (MEC), instaurando-se pelo caso uma auditoria no próprio PNLD. Já o portal de notícias Sul $21^{6}$ destaca as "novas diretrizes governamentais" que buscarão "suavizar" os LD por "ter muita coisa escrita", identificando e recomendando a retirada e descarte dos livros desatualizados, obsoletos, ociosos, irrecuperáveis, antieconômicos ou em desuso. Inclusive, o descarte deve ocorrer de livros que ainda estão armazenados e embalados, pois cerca de 2,9 mil destes materiais didáticos estão "vencidos" (2005 e 2019).

\footnotetext{
5 Fonte: https://gauchazh.clicrbs.com.br/geral/noticia/2019/12/sem-uso-livros-didaticos-do-governo-sao-vendidospara-reciclagem-ck3xni377005h01qhlwb0jdgv.html Acesso: 27/01/2020.

6 Fonte: https://www.sul21.com.br/ultimas-noticias/politica/2020/01/apos-criticas-de-bolsonaro-mec-vai-descartarlivros-didaticos/ Acesso: 27/01/2020.
}

Periódico Horizontes - USF - Itatiba, SP - Brasil - e020007 
Segundo Magda Soares (2002), os livros didáticos para o ensino de língua portuguesa inicialmente eram poucos. A Antologia Nacional, de Fausto Barreto e Carlos de Laet, foi um livro muito utilizado nas aulas de Língua Portuguesa nos séculos XIX e XX. A primeira edição é de 1895, e a última é de 1968/69. Era uma coletânea de textos que deveria ser estudado com apoio de uma gramática normativa e não apresentava exercícios ou atividades. O modelo atual de LDP com exercícios, interpretação de textos, redação ou uso de imagens consolidou-se apenas na década de 1970. Quanto aos textos de cunho literário, estes sempre fizeram parte desse gênero, ainda que com a concepção de que para que houvesse uma produção escrita "correta" dever-se-ia imitar os modelos consagrados.

Ao final da década de 1990, com os Parâmetros Curriculares (PCNs) e outros documentos oficiais, a concepção de texto passou a estar atrelada à critérios de coerência, coesão, contexto e produzido de diversos modos, desde o escrito até o oral e permeando pelos textos com imagens, hoje denominados multimodais. Segundo essas propostas mencionadas, o principal objetivo do LDP é de contribuir para o ensino, para que os usuários da língua desenvolvam e expandam sua competência comunicativa, e consigam empregá-la em diversas situações de comunicação, produzindo e interpretando textos diversos. Atualmente, o modelo de LDP consiste em apresentar uma coletânea de textos, atividades instrutivas e análise sobre a língua(gem), contemplando os eixos de leitura, produção textual, conhecimentos linguísticos e oralidade (BRASIL, 1997).

O PNLD (BRASIL 2017, p.29) indica em sua proposta a necessidade da presença de textos visuais e multimodais em livros didáticos, com intuito de ampliar as experiências linguísticas no espaço escolar, visando explorar os aspectos multilinguísticos, como as cores, design, diagramação, traços, linhas, espaços etc, além da utilização de mapas, gráficos, infográficos, capas, charges, poemas visuais e concretos, fotografias, cartazes e outros gêneros relacionados à leitura intertextual e multimodal. Destaca-se também, que em grande parte das obras aprovadas pelo PNLD, os alunos "poderão, também, perceber as relações entre a linguagem verbal e a visual em textos multimodais, pois eles estão presentes na coletânea e são explorados em atividades e/ou seções didáticas específicas" (BRASIL, 2017, p.31).

Contudo, procurar conceber as múltiplas funções e concepções do LD não é uma questão equânime entre os pesquisadores. Em cada perspectiva, verifica-se um conceito ou 
reflexão sobre esta importante ferramenta pedagógica. Nesta pesquisa, buscando ir além da constituição do LD enquanto suporte (MARCUSCHI, 2008), concorda-se com Martin e Rose (2006), importantes teóricos e estudiosos dos gêneros discursivos, numa perspectiva sistêmicofuncional, ao conceituar o livro didático como um macrogênero, um complexo que se constitui de vários outros gêneros. No LD, os gêneros adquirem outro caráter daquele que originalmente foram produzidos, situam-se em outro contexto, possuem outro objetivo e outra relação com o receptor. Os gêneros, como produtos de um contexto de cultura (HALLIDAY; HASAN, 1976 citado em Soares, 2016), são modos de interação produzidos em uma dada esfera de atividade humana, construções de natureza híbrida e dinâmica (BUNZEN JÚNIOR, 2005). O livro didático, nesta perspectiva, atende a esta concepção, pois é um material relevante e multifuncional utilizado para a realização da língua e que determina as práticas em sala de aula, muitas vezes sendo o único ou mais importante material utilizado no processo de ensino-aprendizagem. Hemais (2015), por exemplo, coaduna-se com a perspectiva e também adota essa concepção ao tratar dos gêneros discursivos (e multimodais) para o ensino de inglês.

A coleção selecionada para esta pesquisa trabalha com a proposta de ensino via gêneros textuais, partindo do pressuposto de que o conhecimento e domínios das diversas esferas dos gêneros textuais ampliam e enriquecem a competência de não só produzir textos orais e escritos, mas também multimodais. É importante destacar que o LD, independente de sua concepção ou funcionalidade, é um instrumento hábil para práticas de multiletramento, ainda que na sua atual conjuntura e sistema, tenham-se muitas dificuldades para realizá-las, conforme se discutirá a seguir.

\section{O livro didático como instrumento para práticas de multiletramento}

O conceito de letramento possui inter-relação com as práticas sociais que permeiam as funções de leitura e escrita. Segundo Soares (2002, p.144, grifo nosso): “alfabetização ocupa-se da aquisição da escrita por um indivíduo enquanto letramento focaliza os aspectos sóciohistóricos da aquisição de um sistema escrita por uma sociedade". Entretanto, é necessário na contemporaneidade ressaltar a importância de desenvolver competências para ler e produzir textos com diferentes modos e recursos semióticos (JEWIT, 2011). Kress (2010, p.141; KRESS, 
van LEEUWEN, 1996) afirmam que os livros têm mudado tal como as funções e as relações sociais com os leitores ou o espaço escolar também têm se modificado. Tais mudanças podem ser vistas não apenas no conteúdo, mas no design. Um novo layout com imagens coloridas, fotografias, desenhos, pinturas e textos que incluem a modalidade escrita e visual estão configurados nos atuais livros didáticos. Proporcionam assim, um redimensionamento de práticas visuais que tornam o texto muito mais interativo e dialógico em sua totalidade.

Kress e van Leeuwen (1996, p.21) distinguem dois modos de letramento visual: a comunicação visual como um elemento subserviente e marginalizado à linguagem, considerando as imagens meras ilustrações. E outro modo de letramento em que a linguagem oral e escrita está lado a lado às formas de representação visual em um dado contexto de cultura. Isso é notório ao se observar os LD ao longo das últimas duas décadas. Diversos fatores, incluindo socioculturais, têm mudado a função da imagem em contexto contemporâneo, ganhando um papel de destaque e tornando-se impossível apreendê-la apenas com um letramento de natureza puramente verbal. É necessário ir além, ou seja, multiletrar os atores sociais. O conceito elaborado por um grupo de pesquisadores de Londres associa o conhecimento linguístico-discursivo com o conhecimento visual, espacial, digital e crítico (CAZDEN, COPE, et. all, 1996). Este conceito englobaria duas multiplicidades, conforme também explanado por Rojo e Batista (2015, p. 135): de culturas (multiculturalismo) e de linguagens e mídia (multissemiose). E a interação entre estes conhecimentos é denominada de letramento multimodal:

A pedagogia do multiletramento, em contraste ao mero letramento, enfoca nos modos de representação que vão muito além de apenas a linguagem verbal. [...] Cria-se assim, um tipo diferente de pedagogia, uma em que a linguagem e os outros modos de significado são vistos como recursos dinâmicos de representação, constantemente sendo refeitos pelos usuários que os produzem a fim de alcançarem seus propósitos culturais (CAZDEN; COPE; et. all, 1996, p.64).

Deve-se estimular cada vez mais a prática do multiletramento, pois cotidianamente estamos em contato com múltiplas linguagens e modos semióticos, inclusive a Base Nacional Comum Curricular (BNCC) (BRASIL, 2016), mais recente documento oficial brasileiro de diretrizes educacionais, amplia os Parâmetros Curriculares Nacionais (BRASIL, 1997) e destacam 
ainda mais as estratégias linguístico-discursivas e semióticas que permeiam os mais diversos gêneros, instigando o trato com o hipertexto e também com ferramentas de edição, áudio, vídeo e imagem. Os conhecimentos sobre a língua continuam tendo grande relevância, mas não devem ser tratados de forma dissociada aos os textos e as diversas semioses.

Numa perspectiva mais geral, vê-se que todos os significados produzidos são multimodais (CAZDEN; COPE; et. al, 1996, p. 81; DIONÍSIO, 2010, p. 139). Todo texto escrito é visualmente desenhado pela escolha da fonte, do layout das páginas, bem como o discurso oral em que a sonoridade (entoação, grau e altura da voz/ do som) faz com que se possam empreender novos significados e justifica ainda mais a importância de se repensar a perspectiva multimodal. O que se deve salientar é que existem níveis de manifestação, produção e organização multimodais, há gêneros mais visualmente informativos outros menos visualmente informativo (DIONÍSIO, 2010, p. 142), por exemplo, um meme ou uma charge em comparação a um e-mail ou um artigo acadêmico.

Partindo dessa concepção, a seguir, verificam-se algumas definições gerais quanto ao trato do texto verbal, visual e com outras semioses.

\section{Texto verbal, visual e outras semioses}

Halliday e Hasan (1976 citado em SOARES, 2016) cunham a palavra 'texto' para referirse a "qualquer passagem de qualquer extensão, uma unidade semântica de linguagem em uso", ou seja, "é qualquer instância da linguagem, em qualquer meio, que faz sentido a alguém que conhece a linguagem". Com isso, pode-se também definir as imagens como textos, pois são unidades de sentido utilizadas por atores sociais a fim de transmitir uma dada mensagem em um dado contexto situacional e cultural.

É perceptível, no entanto, as distinções entre um texto verbal e um texto não verbal, presentes em diversos materiais e livros didáticos. De um modo geral, um texto verbal é construído pelo uso da escrita ou da fala no ato comunicativo. Já ao se utilizar a linguagem não verbal opta-se pelo uso de imagens, figuras, desenhos, símbolos, os gestos, entre outros. Apesar dessa distinção entre texto verbal e não verbal ser aparentemente clara, no âmbito das linguagens não verbais tem-se, por exemplo, ilustrações, imagens, desenhos, figuras, 
fotografias, símbolos e muitas outras terminologias que podem causar dificuldades de concepção. Uma ilustração é uma imagem? Um desenho é uma ilustração? Uma figura é um desenho? Abaixo, no Quadro 1, tem-se os significados para estes termos segundo o dicionário Caudas Aulete:

Quadro 1. Termos relacionados à natureza visual

\section{Significados para termos relacionados à natureza visual}

Imagem: 1. Reprodução visual de um objeto ou de um ser com o auxílio de aparatos técnicos; 2. Representação visual ou plástica de uma divindade. 3. Reprodução de pessoa ou objeto em uma superfície com capacidade refletora; 4. Representação mental de pessoa, objeto ou acontecimento; recordação. 5. Aquilo que simboliza alguma coisa (p.474).

Desenho: 1. Representação de coisas ou pessoas por meio de traços feitos a lápis, tinta, etc. sobre papel.

2. Arte e técnica dessa representação; 3. Feitio, configuração (p.276).

llustração: 1. Ação ou resultado de ilustrar; 2. Conjunto de imagens (desenho, gravura, etc) que acompanham um texto; 3. Conhecimento, saber (p.474).

Figura: 1. Desenho, pintura, gravura etc. de pessoa, animal ou coisa; ilustração; 2 . A forma de um corpo; 3. Pessoa; 4. Forma geométrica; 5. Representação simbólica da duração de um som (p.409).

Fonte: Caldas Aulete Dicionário (2012)

Ao também consultar o Glossário de Termos Multimodais ${ }^{7}$ foi possível identificar apenas duas destas quatro categorias elencadas, imagem e desenho: A imagem (image) é caracterizada como uma reprodução de algo que sustenta características de semelhança. Um termo utilizado para se referir a muitas coisas diferentes, por exemplo, fotografias, desenhos, pinturas, filmes, representações 3D, fotos no espelho, entre outras. Já o desenho consiste em traços e linhas inscritos para fins expressivos, informativos e comunicativos. Difere de outros por não possuir notação estritamente regularizada. As qualidades visuais e referenciais dos desenhos mudam de acordo com as especificidades históricas, culturais e sociais. Os desenhos variam de imagens, esboços e rabiscos a diagramas científicos, mapas geográficos e projetos arquitetônicos.

Conforme é possível observar, muitos destes termos podem ser caracterizados como sinônimos. Defini-los como texto visual ou imagético é generalizar que as imagens podem constituir significados, assim como os textos verbais. Falco (2016) conceitua, por exemplo, o

\footnotetext{
7 O Glossário de termos multimodais, em inglês, Glossary of Multimodal Terms, é um recurso online para pesquisadores das áreas da semiótica e multimodalidade. Os conceitos são elaborados a partir de renomados pesquisadores e disponível em: https://multimodalityglossary.wordpress.com/. Acesso para o trabalho em: $11 / 01 / 2019$.
} 
termo ilustração como uma imagem utilizada para "acompanhar, explicar, acrescentar informação, sintetizar ou, até decorar. É a forma não textual de passar uma dada mensagem e geralmente apenas acompanha um texto". A ilustração não necessariamente tem que ser um desenho, pode ser uma foto, uma colagem ou até uma pintura, "não possuem função isoladamente, mas só em relação a um texto" (CAMARGO, 1999). Já a imagem deriva de um termo latino que se refere à figura, representação, semelhança ou aparência de algo. É a representação visual de um objeto através de técnicas, por exemplo, pintura, fotografia, desenho, vídeo e outros. Apesar da ausência de equidade ao conceber estas terminologias e funcionalidades em diversas perspectivas concorda-se que tanto o texto verbal quanto o visual são multimodais. Ao se utilizar uma fonte em negrito, sublinhado, CAIXA ALTA, realce, transmite-se significados, assim como, ao se mudar a cor, a sombra, a luz de uma fotografia ou quando se gesticula ou se muda a entonação ao falar. Estes modos de produção são acionados pelos atores sociais via gêneros textuais.

Esta pesquisa fundamenta-se na Teoria Semiótica Social da Multimodalidade (TSSM), de Kress e van Leeuwen (2006 [1996]) que adota esse diálogo de significados entre os modos semióticos e atribui categorias analíticas e instrumentos para compreendê-los, conforme se explana a seguir.

\section{A Teoria Semiótica Social da Multimodalidade (TSSM) e a Gramática do Design Visual (GDV)}

A Teoria Semiótica Social parte do claro interesse no significado em todas as formas, não apenas os verbais (KRESS, 2010). Todos os modos semióticos devem ser considerados e contribuem para a construção do signo (KRESS, 2010, p.54). Sabe-se que a gramática tradicional não foi elaborada com o intuito de abarcar estes sistemas semióticos, já que a proposta recai nas estruturas sintáticas, morfológicas formais e verbais. Entretanto, os significados podem ser realizados tanto visualmente quanto verbalmente (KRESS, van LEEUWEN, 1996, p.2). E a partir disso então, formulou-se a Gramática do Design Visual (GDV), em inglês, Reading Imagens- The Grammar of Visual Design, de Gunther Kress e Theo van Leeuwen (1996), com segunda edição publicada em 2006. A obra visa estabelecer um inventário de elementos e funções visuais estabelecidas em uma dada cultura, sobretudo a 
Ocidental. Esta gramática é uma dimensão da Semiótica Social e inspirada nas categorias e concepções de Michael Halliday (1994) e a Linguística Sistêmico-Funcional (1994, p.5). As metafunções hallidayanas: ideacional, interpessoal e textual são reconfiguradas em significados representacional, interacional e composicional, respectivamente. No Quadro 2, abaixo, se apresentam as categorias analíticas relacionadas à cada tipo de significado conforme estabelecido pela GDV:

Quadro 2- categorias analíticas dos significados via GDV
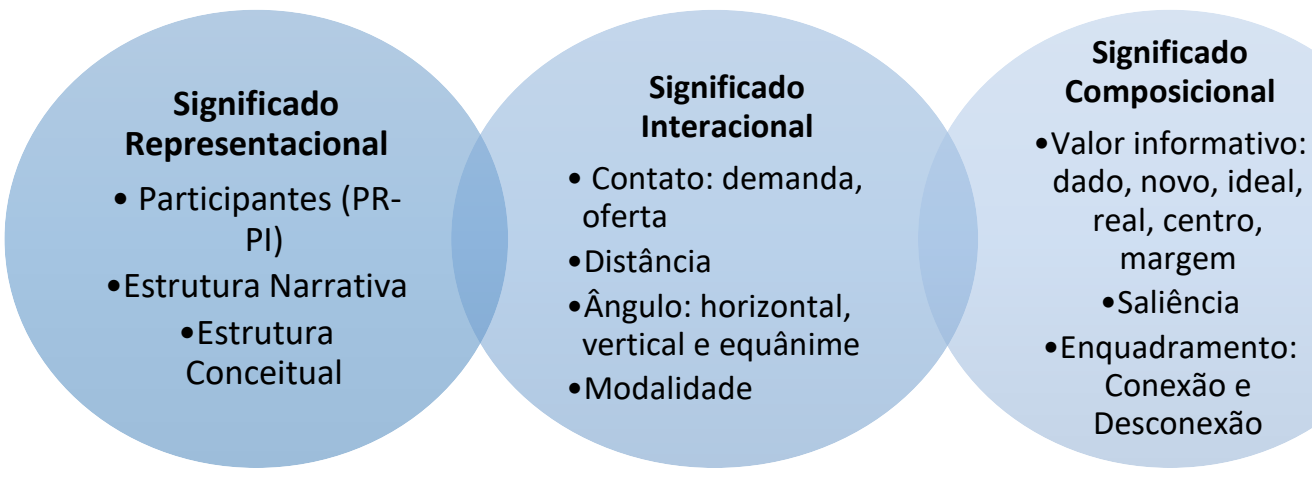

Fonte: Kress e van Leeuwen (2006 [1996]), adaptado.

As semioses e, consequentemente, a imagem significam, ou seja, constroem informações de natureza semântica. Esses significados são categorizados pela Gramática do Design Visual (GDV) em três tipos de significados. O Significado Representacional relaciona se às potencialidades de representação via sistema semiótico. Na GDV, pode ser analisado a partir de duas perspectivas: narrativa, ou seja, quando os participantes estão conectados por um vetor (a direção do olhar, o movimento gestual) que estabelece um tipo de ação entre dois ou mais participantes. Ou em estruturas conceituais, estruturas mais ou menos estáveis e que não apresentam vetor, subdividindo-se em classificatório, analítico e simbólico. Os participantes podem estar representados nas estruturas, chamado de Participante Representado (PR) ou interagindo com o texto (ao ler, ao olhar, ao produzir), considerados Participantes Interativos (PI).

O segundo tipo de Significado estabelecido pela GDV é o Interacional. Correlaciona-se à metafunção interpessoal em LSF e, com isso, trata das relações entre os produtores e receptores (leitores, observadores, público em geral) de um dado signo. Essas relações podem ser construídas por contato, distância, ângulo e modalidade entre os participantes. O processo 
interacional por contato é estabelecido por um vetor formado pela direção do olhar conectando os participantes ao observador. Quando há um contato direto com o observador, constrói-se um contato por demanda. Já quando não há este contato direto pelo olhar/movimentos e o participante representado (PR) é um item contemplativo se estabelece um contato por oferta. A distância é outra categoria de suma importância nessa perspectiva. São convenções que a estabelecem no evento discursivo, por exemplo, os planos abertos, médios e fechados. Tal como a distância, o ângulo também atribui um tipo de relação entre os participantes e determina assim, níveis de engajamento (ângulo horizontal) ou estabelecendo poder entre o PR e o PI (ângulo vertical). Kress e van Leeuwen (2006, p.160) também destacam a importância da modalidade na composição visual. É uma categoria que constrói valores de realidade/naturalidade ou abstração de um dado texto. E os autores estabelecem como elemos analíticos marcadores que auxiliam nesta construção, por exemplo, a saturação, diferenciação e modulação de cores e os níveis de contextualização, representação, profundidade, iluminação e brilho.

Inter-relacionado aos significados anteriores, por último, apresenta-se o Significado Composicional, a construção do texto em si, o que configura o todo significativo, aliando tanto representação como interação (KRESS e van LEEUWEN, 1996, p.176). Nesta dimensão é possível analisar a congruência dos elementos representacionais e interacionais e esta relação pode ser apresentada por três categorias: o valor de Informação (informação dada, à esquerda; informação nova, à direita; acima, abaixo, centro, margem). Está bastante relacionado ao layout, o espaço visual do texto. Além do valor de Informação, há outros critérios que marcam a estrutura composicional de um texto: a saliência, estabelecida a partir de elementos modalizadores (foco, tamanho, contraste de cores, distância e ângulo); e o enquadramento, um elemento de conexão entre a mensagem e o PI, por exemplo, molduras, espaços vazios, vetores e similaridades de cores.

Com estas categorias, propostas na GDV, Kress e van Leeuwen oferecem um aparato para análise do texto visual e multimodal e buscam diminuir as barreiras entre os estudos da linguagem verbal e os estudos das linguagens visuais e multimodais.

\section{Instrumentos metodológicos: a coleção Português Linguagens, de William Cereja e Thereza Cochar Magalhães (2015): breve contextualização}


Para a análise toma-se a Coleção Português Linguagens do Ensino Fundamental II, dos autores William Cereja e Thereza Cochar Magalhães, ed. Saraiva (2015) ${ }^{8}$. O LD tem sido utilizado nas escolas públicas e particulares da cidade de Manaus-AM e também aprovado pelo guia do PNLD.

Figura 1: Coleção Português Linguagens do Ensino Fundamental II
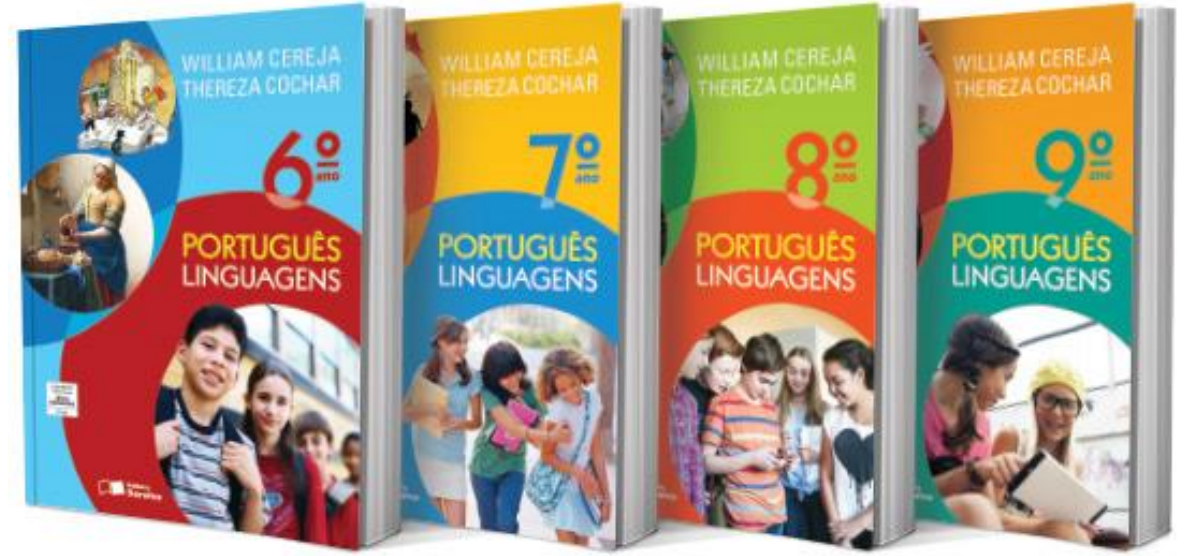

Fonte: http://pnld.editorasaraiva.com.br/obra/portugues-linguagens-2/.

Segundo Alves (2015), a partir de dados do Portal do FNDE (Fundo Nacional de Desenvolvimento da Educação) ${ }^{9}$, esta coleção foi a mais distribuída no Brasil em 2014. Portanto, o livro selecionado como objeto de análise deste trabalho tem grande abrangência também, no território nacional. A coleção é considerada Tipo 2, pois inclui em sua proposta de trabalho com objetos educacionais digitais.

Neste recorte analítico partiu-se do pressuposto de que os LD na medida em que progridem no âmbito educacional, ou seja, da educação infantil ao Ensino Médio, eles tendem a subtrair o espaço e função das imagens a meras ilustrações, sobressaindo-se o elemento verbal, os aspectos gramaticais, entre outros (KRESS; van LEEUWEN, 2006; KRESS, 2010). Portanto, nesse caso, a coleção composta por quatro livros referentes ao ensino fundamental II (6 ao 9 ano) delimitou-se para análise o que se chamou de "material de transição", ou seja, o livro didático utilizado pela turma de 6ำ ano, considerado uma fase intermediária entre a saída do ensino fundamental I e a entrada no ensino fundamental II. A

\footnotetext{
${ }^{8}$ Fonte: http://pnld.editorasaraiva.com.br/obra/portugues-linguagens-2/. Acesso em 20 de maio de 2017.

${ }^{9}$ www.fnde.gov.br. (Para análise dos dados, consultar dissertação de Alves (2015).
} 
pesquisa subdivide-se em dois momentos. Inicialmente, propõe-se um levantamento de natureza quantitativa da manifestação multimodal na Coleção Português Linguagens. Em seguida, proceder-se-á uma análise qualitativa e interpretativista com base nos teóricos da Gramática do Design Visual (KRESS e van LEEUWEN, 2006), quanto às categorias relacionadas ao significado Representacional, Interacional e Composicional, bem como a identificação de produtores (ilustradores, no geral) nos textos.

\section{Levantamento quantitativo da multimodalidade nos LD de Língua Portuguesa}

Seguindo os níveis de manifestação e organização multimodais propostos por Dionísio (2011, p.142), já referidos anteriormente, para esta análise buscar-se-á gêneros mais visualmente informativos presentes no livro didático do 6ㅇa ano da Coleção Português Linguagens. Toma-se como auxílio para a análise quantitativa o trabalho de Barros e Costa (2012) em que também se propõe o levantamento destes gêneros quantitativamente. No Quadro 3, abaixo, apresentar-se-á os resultados dos gêneros mais recorrentes nesta obra:

Quadro 3- Levantamento quantitativo da manifestação multimodal no livro didático do 6ㅇano

\begin{tabular}{|l|c|c|}
\hline \multicolumn{1}{|c|}{ Manifestação visual e multimodal no livro didático } & $\begin{array}{c}\text { Quantidade } \\
\text { (aprox.) }\end{array}$ & Percentuais \\
\hline Ilustrações $^{10 i}$ & 104 & $30 \%$ \\
\hline Reproduções de fotografias & 80 & $23 \%$ \\
\hline Tirinhas & 57 & $9 \%$ \\
\hline Reproduções de anúncios publicitários & 29 & $5 \%$ \\
\hline Reproduções de capas de livros ou cartazes fílmicos & 18 & $5 \%$ \\
\hline Histórias em Quadrinhos & 18 & $5 \%$ \\
\hline Cartuns & 16 & $4 \%$ \\
\hline Reproduções de pinturas & 13 & $2 \%$ \\
\hline Outros $^{11}$ & 7 & \\
\hline
\end{tabular}

Fonte: elaboração dos autores.

\footnotetext{
10 Neste contexto, consideramos "ilustrações" as representações pictóricas que acompanham outros gêneros como fragmentos de livros, trechos de gêneros textuais, letras de canção, poemas etc.

${ }^{11}$ Salienta-se que, por critério de delimitação, apresentam-se na tabela apenas os gêneros multimodais de maior representatividade, em termos absolutos e percentuais. Esta categoria "Outros" refere-se a símbolos e ícones como logomarcas; infográficos (conteúdo proposto na última unidade); e charges
} 
Nota-se por esse levantamento quantitativo que os livros didáticos ainda transitam entre as perspectivas do letramento visual (KRESS, van LEEUWEN, 2006). Sendo compostos tanto por imagens mais significativas quanto imagens como elementos subservientes, acessórios à conjuntura do texto. Estas são consideradas ilustrações e acompanham o texto verbal, representando $30 \%$ da composição do livro didático analisado. Destas 104 ilustrações selecionaram-se duas páginas que possuíssem tais representações para serem analisadas à luz das categorias da Gramática do Design Visual (GDV), instituindo como uma forma de auxiliar a interpretação desses textos visuais e que estão permeando como textos multimodais.

\section{Abrindo o livro didático}

Imagem 1- Print da página que trata da classificação dos substantivos

\section{Classificação dos substantivos}

Existem diferentes tipos de substantivo. Alguns nomeiam colsas, outros nomeiam pessoas ou sen. timentos. Alguns sao constituidos por uma só palavra, outros por duas ou mais palavras. No estudio gramatical da língua, eles sao classificados, isto e, organkados, de acordo com certas caracteristicas que apresentam. Assim. os substantivos classificarn-se em:

\section{primitivos e derivados}

- Primitivos sào os substantivos que dão origem a outras palavras.

- Derivados sâo os substantivos que se originam de outras palavras

$\begin{array}{lll}\text { telha } & \rightarrow & \text { telhado } \\ \text { ferro } & \rightarrow & \text { ferrugem }\end{array}$

substantivos primitivos

substantivos derivados

\section{simples e compostos}

- Simples são os substantivos formados por apenas uma palavra: luz, mesa. chocolate.

- Compostos sao os substantivos formados por mals de uma palavra: beija-flor, para-raios, pontapé

\section{comuns e próprios}

- Comuns sào os substantivos que se referem a todos os seres de uma espé cie, sem particularizá-los.

\section{Aquele rapaze é muito estranho!}

- Prôprios são os substantivos que nomeiam um ser em particular, destacando-o na espécle ou no grupo por isso sào grafados com letra matùscula

Drácula ficou irritada com sua vitima.

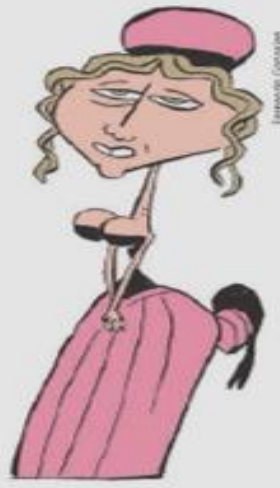

O substantivo rapaz serve para nomear qualquer homem; por isso, é substantivo comum. lá Drá. cula particulariza um homem: por isso, é substantivo próprio.

Fonte: Português Linguagens 60 ano, de William Cereja e Thereza Cochar, 9. ed. 2015, p.93. 
Nesse evento discursivo, observa-se um texto composto pelo modo verbal, apresentando-se um conteúdo gramatical, a classe morfológica de palavras substantivas, e contém uma ilustração parcialmente à direita, representando uma participante (PR) simbolicamente do gênero feminino. Quanto ao significado representacional, não há um vetor de ação, ou seja, o PR está estático, definindo então, como uma estrutura conceitual.

Em relação ao significado interacional, a moça desenhada (PR) não emana contato direto via olhar ao observador, está em distância impessoal ao leitor ou observador do livro (o denominado Participante Interativo (PI)), um item contemplativo, caracterizado como um contato por oferta. Está disposto à direita do texto verbal e exige do leitor uma retomada prévia de uma narrativa relatada nas páginas anteriores, sem a qual não se apreende quem está sendo representada. Em uma relação de leitura vertical, o leitor do LD sempre terá poder sobre o material, o produto, sem nos deter nas condições econômicas e sociais de produção. Quanto ao significado composicional, o texto verbal é mais saliente que o texto visual, e observa-se uma desconexão direta entre esses textos, pois um trata dos substantivos simples/compostos, comuns/próprios, e o texto visual, informativamente, não traz quaisquer contribuições significativas ao sentido geral do texto. Com isso, gera-se certa incoerência e “incoesão" verbo-visual. Uma possível forma de amenizar esses aspectos seria transpor o negrito grafado, Drácula e o rapaz, nos textos verbais para a palavra vítima ou moça, a quem narrativamente se refere à ilustração, ou então, trocá-la para uma figura do gênero masculino ou mais próximo das frases à esquerda.

Identifica-se no texto visual o produtor, Fernando Gonsales, em horizontal, em fonte tipográfica mínima, à direita da ilustração. A representação remete às mulheres de séculos passados, que utilizavam vestidos em estilo francês corselê. Uma representação, contudo, de modo muito caricatural e sem preocupação com contornos e dimensões. Nesse caso, a modalidade visual revela-se pelas cores rosa, preto e tons de bege. Não apresenta plano de fundo, ou seja, descontextualizado, segundo categorias da GDV. Ainda que seja uma imagem extraída de uma narrativa anterior, não demanda práticas ao leitor neste novo evento/ nova página e, com isso, não cumpre uma função afluente ao texto. Todas as orações renomeiam um personagem masculino, Drácula. Inserir um texto imagético-ilustrativo referindo-se a este personagem poderia tornar a conjuntura do texto mais coerente e coesa tanto nos aspectos 
verbais quanto visuais.

Texto 2- Print da página que trata de encontros vocálicos

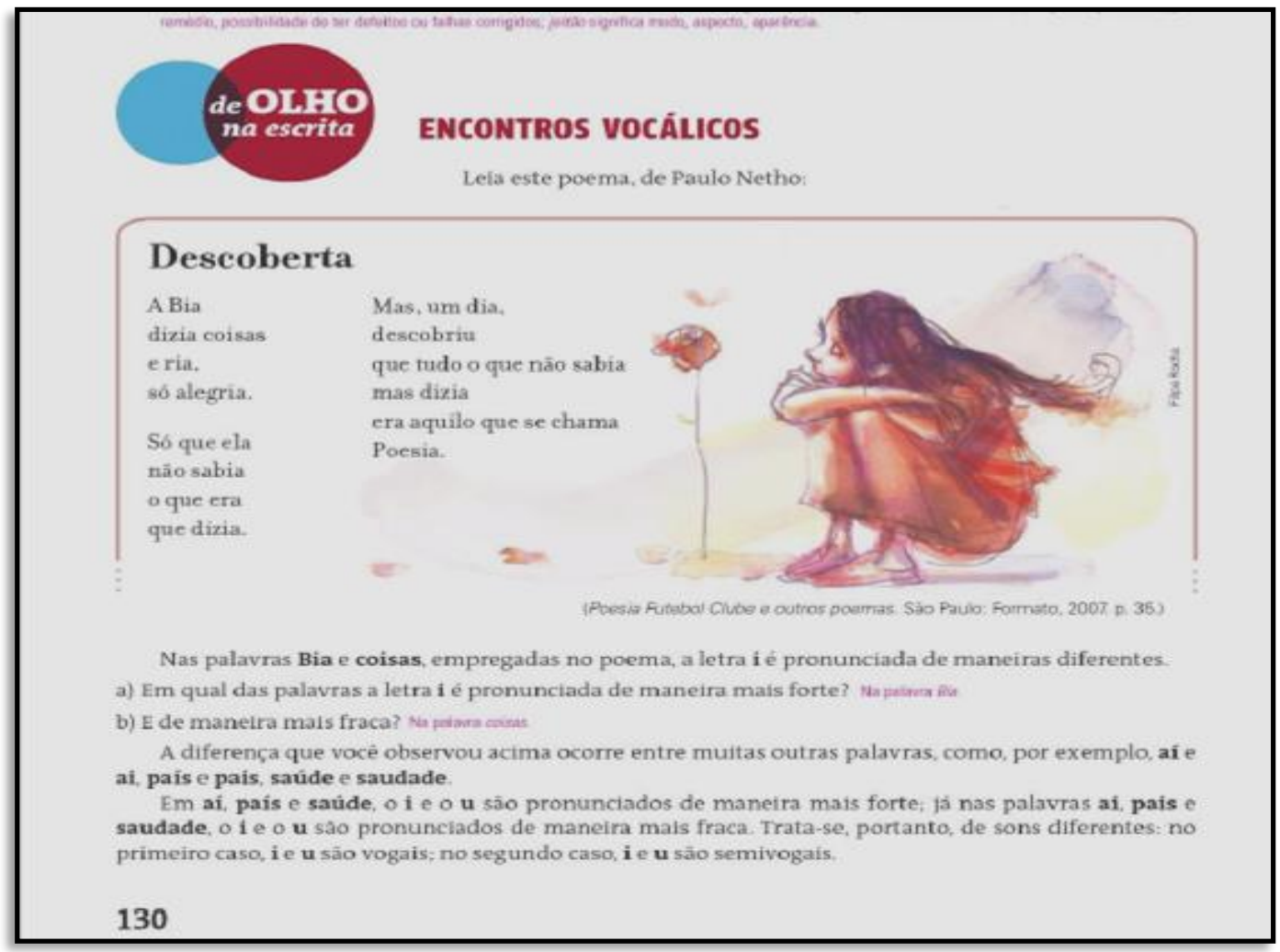

Fonte: Português Linguagens 6o ano, de William Cereja e Thereza Cochar, 9. ed. 2015, p.130.

Outro caso, semelhante à Imagem 1, é a Imagem 2, acima, que acompanha o Poema, de Paulo Netho, Descoberta. Nesse texto, o PR apresenta simbolicamente uma jovem do gênero feminino. Essa PR não emana contato pelo olhar ao PI, ou seja, um estabelece um Contato, apenas por Oferta. Está disposto também à direita do texto verbal, configurando-se como uma informação Nova. Parcialmente se deduz de que a PR é Bia, a menina relatada no Poema. O texto verbal é mais saliente do que o texto visual, está acima do plano de fundo da imagem. Vê-se uma desconexão parcial entre o texto verbal e visual dada ao conteúdo - Encontros Vocálicos, informação Ideal (acima) em destaque na conjuntura textual. É possível identificar abaixo o produtor do texto verbal, bem como o do texto visual em fonte tipográfica mínima, na horizontal da imagem. A imagem, de natureza abstrata, é desvelada por pinceladas em modulação dos tons de marrom e laranja. Não há uma preocupação com contornos e com a 
contextualização do plano de fundo do texto visual. Observa-se também que nessa estrutura representacional, ocorre um processo narrativo reacional, onde o reator (PR), a jovem menina, está com o olhar direcionado ao fenômeno (flor), ainda que de natureza não naturalista, pois se constitui de um desenho de um ser humano e não uma fotografia, por exemplo.

Resguardando-se às devidas licenças poéticas que se permitam no gênero poesia, a imagem continua exercendo pouca função direta ao todo textual. O significado produzido é mínimo e poderia ter sido mais produtivo. Se fosse retirada a imagem, o poema manteria seu sentido, portanto, nesse caso tem apenas função acessória, ilustrativa, aquém das recentes concepções de um texto multimodal.

Numa perspectiva macro, ainda é possível verificar a representação estereotipada em ambos os textos (1 e 2) da figura feminina. Estereótipo por estar distante de retratar o multiculturalismo e a heterogeneidade do povo brasileiro. Uma das causas possíveis a esta questão, ainda que resguardadas às novas políticas mercadológicas, é a "importação" de livros didáticos. No Amazonas, muitos dos livros ainda são produzidos nas regiões sul e sudeste, o que dificulta em partes a absorção tanto no tratamento verbal quanto visual das práticas atreladas ao contexto e às práticas discursivas locais. Entende-se também, que a leitura, interpretação e produção de textos visuais e/ou multimodais leva o leitor a agenciar múltiplos conhecimentos, tornando uma atividade de alta complexidade, cabendo ao professor, na escola, a função de mediar esses conhecimentos e oferecer aparatos para operacionaliza-los, pois é uma demanda social atual saber ler e produzir textos em diversas linguagens e semioses.

Conforme pôde ser observado nos textos analisados, o LD em questão ainda utiliza de modo parcial, as imagens como elemento acessório, resgatando o antigo letramento descrito por Kress e van Leeuwen (2006). Com as devidas mudanças, o LD poderia sim contribuir para um melhor desenvolvimento das múltiplas competências (semiótica, visual e tecnológica) e promovendo também práticas de multiletramento. A escola, os professores, as instituições ainda necessitam e muito de condições para lidar com as novas práticas da contemporaneidade, a imagem é uma delas. A Base Nacional Comum Curricular (BNCC) (BRASIL, 2016), o mais recente documento de diretrizes educacionais do Brasil, orienta o tratamento da Língua Portuguesa aos gêneros que circulam nas mais diversas esferas, tendo como foco as estratégicas linguístico-discursivas e também semióticas utilizadas para 
argumentar e/ou representar. Destaca-se também a compreensão "dos efeitos de sentido produzidos por recursos de diferentes naturezas, para depois se alcançar a dimensão imagética" (BNCC, 2016, p.136).

\section{Considerações finais}

Os livros didáticos são um meio de comunicar o discurso pedagógico. Diferentemente de outros textos, são leituras obrigatórias durante a jornada escolar e é, com certeza, um condicionante de poder, que apenas refletem os interesses de seus produtores e instituições, conforme afirma Van Dijk (2008). Dificilmente buscam polemizar, criticar ou dar vozes a outros discursos. Fato que destoa do atual momento da educação brasileira em que se busca formar alunos críticos-reflexivos, alunos que têm cada vez mais acesso a uma gama de informações provindas de infinitos meios, principalmente, tecnológicos e que apresentam o uso de múltiplos modos semióticos para transmitir essas informações.

No atual modelo, o LD ainda se centra, em grande parte, na visão de uma sociedade grafocêntrica, gramatical, relegando, de um modo geral, as variações da língua e da(s) linguagem(ns). Logo, torna-se necessário que se atualize o LD em termos linguísticos, semânticos, semióticos, contextuais e culturais, para que assim possa atingir e interagir com uma gama de atores sociais que a ele recorrem como um importante suporte de ensino no Brasil.

Convém reiterar que a utilização de gêneros mais visualmente informativos, por exemplo, charges, tirinhas, HQs, publicidades também é feita não só pelo LD em análise, mas por outros, e a utilização se dá por exercícios, aberturas de capítulos, atividades de pesquisa, portanto, estimulam o desenvolvimento de outras competências e tratam a imagem em um nível de significação mais ampla. Contudo, ainda se "ilustra" muito os textos, procurando deixálos mais ornados esteticamente. Arquitetar o LD como uma escolha mais apropriada de imagens que coadunem parcialmente ou totalmente ao conteúdo proposto ou que possam deixar a imagem como o modo de significar o conteúdo pode ser um "caminho" no meio das pedras que ainda se tem de percorrer, lembrando o clássico poema de Carlos Drummond de Andrade.

Na acepção de Van Dijk, "o discurso educacional é o mais influente na sociedade" 
(2008). Portanto, ainda que com muitos avanços tecnológicos, de conteúdos e design que não se pode desmerecer, circunda ainda muitos estereótipos e concepções tradicionais acerca da língua e linguagens. Seja em seu conteúdo, forma, estrutura, entre outros aspectos, que ainda carecem de muitas reflexões. Na atual conjuntura, o Brasil tem buscado (re)formular seus parâmetros, construir "novos" (BRASIL, 2016), destacando cada vez mais a importância do uso de textos híbridos, multissemióticos ou multimodais a partir dos diversos gêneros, como núcleo do ensino de Língua Portuguesa. Mas vê-se que tanto a formação dos professores quanto a produção dos materiais pedagógicos ainda necessitam de um aporte e de (re)formulações. Algo que as perspectivas da Teoria Semiótica Social da Multimodalidade (TSSM), a Gramática do Design Visual (GDV) e tantas outras perspectivas semióticas poderiam auxiliar e suprir essas demandas.

É inconcebível de que o tratamento e a leitura de textos multimodais exercendo grande papel semântico ao evento discursivo fiquem restritos a áreas, por exemplo, da matemática, geografia, história, biologia, em que os gráficos, tabelas, imagens representam, muitas vezes, o que não é possível "dizer" apenas em palavras e sentenças. Já os livros didáticos de Língua Portuguesa carecem de refinamento quanto à leitura, interpretação e, também, produção de textos multimodais. Trazer a conhecer a teoria que a GDV apresenta também pode contribuir para tornar os professores mais críticos ao selecionarem os materiais que são ofertados aos alunos ao longo dos anos escolares. Mudar a ótica de que as imagens simplesmente ilustram ou ancoram de modo didático o texto é o primeiro passo nesse desafio de estudar as inúmeras semioses que permeiam não só os livros, mas todos os recursos de comunicação e aprendizagem de que a sociedade contemporânea dispõe.

Teve-se acesso, para essa pesquisa, à primeira edição da Coleção Português Linguagens para o sexto ano publicada em 1998 pela editora Atual. O que se observa é uma clara manutenção, ainda que com as devidas atualizações socioculturais, de um padrão estético, editorial, de conteúdos e produção deste livro, tendo a imagem, muitas vezes, apenas função acessória.

Em uma sociedade cada vez mais imagética e semiótica, é necessário repensar as práticas realizadas nas escolas em relação ao livro didático. Não é suficiente letrar, mas multiletrar nossos alunos e, para isso, necessita-se de meios, instrumentos para efetivar essas 
práticas. Contudo, o que se ainda observa quanto ao tratamento de textos visuais, híbridos e multimodais segue uma perspectiva de desalinhamento. É importante ao elaborar o evento discursivo, observar o todo/a conjuntura textual, incluindo-se o design, o layout, em como cada modalidade pode significar, amalgamando-as para produzir sentido(s) relevante(s) ao leitor.

\section{Referências}

ALVES, S. P. Os gêneros nos livros didáticos de Português: concepção discursiva ou textual? Dissertação (Mestrado- PPGEL) - Universidade Federal Fluminense, 2015.

AULETE, C. Dicionário escolar da língua portuguesa. GEIGER, P. (Org.). Rio de Janeiro: Lexikon, 2012.

BAKHTIN, M. Estética da criação verbal. São Paulo: Martins Fontes, 2003.

BARROS, C. G. P.; COSTA, E. P.M. Os gêneros multimodais em livros didáticos: formação para o letramento visual? Rev. Bakhtiniana, São Paulo, p.38-56, jul./dez. 2012.

BAUMAN, Z. Tempos Líquidos. Trad. Carlos Alberto Medeiros. Rio de Janeiro: Zahar. 2007.

BAWARSHI, A. S.; JO REIFF, M. Gênero: história, teoria, pesquisa, ensino. Trad. Benedito G. Bezerra et. al. São Paulo, Parábola, 2013.

BRASIL. Ministério da Educação. Secretaria de Educação Fundamental. Parâmetros curriculares nacionais: introdução aos parâmetros curriculares nacionais Brasília, DF:MEC/SEF, 1997.

Disponível em: http://portal.mec.gov.br/seb/arquivos/pdf/livro01.pdf. Acesso em: julho. 2018.

BRASIL. Ministério da Educação. Secretaria da Educação Básica. Base nacional comum curricular. Brasília, DF, 2016. Disponível em:

http://basenacionalcomum.mec.gov.br/\#/site/inicio. Acesso em: agosto. 2018.

BUNZEN JÚNIOR, C. S. Livro didático de língua portuguesa: um gênero do discurso. Dissertação (Mestrado PPGLA- IEL)- Campinas, 2005.

CAMARGO, L. A relação entre imagem e texto na ilustração infantil. 1999. Disponível: http://www.unicamp.br/iel/memoria/Ensaios/poesiainfantilport.htm Acesso: 19 jul. 2018.

CAZDEN, C.; COPE, B. et al. A pedagogy of multiliteracies: designing social futures. Harvard Educational Review; 1996. 
CEREJA, W. R.; MAGALHÃES, T. C. Português Linguagens. 6 ano. 9. ed. Saraiva: São Paulo- SP, 2015.

DIONÍSIO, A. P. Gêneros textuais e multimodalidade. In: KARWOSKI, A. C; GAYDECZKA, B; BRITO, K. S. (Orgs.). Gêneros textuais: reflexões e ensino, 2011, p. 137-152.

DIONÍSIO, A. P.; MACHADO, A. R.; BEZERRA, M. A. Gêneros textuais e ensino. São Paulo: Parábola Editorial, 2010.

FALCO, R. O que é ilustração? Disponível em: http://rodrigofalco.com.br/o-que-e-ilustracao. 01/08/2016. Acesso: 19 jul.2018.

FROW, J. Genre. London: Routledge, 2006.

HALLIDAY, M. A. K. An introduction to functional Grammar. 3. ed. London: Hodder Education, 2004.

HEMAIS, B. J. W. Gêneros discursivos e multimodalidade: desafios, reflexões e propostas de ensino de inglês. São Paulo: Pontes, 2015.

JEWITT, C. The Routledge handbook of multimodal analysis. London: Routledge, 2009.

KRESS, G. Multimodality. A social semiotic approach to contemporary communication. London: Routledge, 2010.

KRESS, G.; van LEEUWEN, T. Reading images: the grammar of visual design. London; New York: Routledge, 1996.

KRESS, G.; van LEEUWEN, T. Reading images: the grammar of visual design.2. ed. London; New York: Routledge, 2006.

MARCUSCHI, L. A. Produção textual: análise de gêneros e compreensão. São Paulo: Parábola Editorial, 2008.

MAROUN, C. R. G. B. A multimodalidade textual no livro didático de Português. Dissertação de (Mestrado- PPGL- UnB), Brasília, 2006.

ROJO, R.; BARBOSA, J. P. Hipermodernidade, multiletramentos e gêneros discursivos. São Paulo: Parábola Editorial, 2015.

SILVA, R. C. Representações do livro didático de inglês: análise dos discursos de produtores e usuários com base na linguística sistêmico-funcional. Tese (Doutorado-Dpt. Letras- PUC)- RJ, 2012.

SILVA, J. S.; MARTINS, N. B. Análise multimodal - estudo dos recursos semióticos em textos de 
livro didático do 7ํano sob a perspectiva sistêmico-funcional. Domínio de Linguagem, Uberlândia, v.11, n.3, jul./set. 2017.

SOARES, M. Novas práticas de leitura e escrita: letramento na cibercultura. Educ. Soc., Campinas, v.23, n.81, p.143-160, dez. 2002.

SOARES, N, M. M.; VIEIRA, J. A. Representação multimodal dos atores sociais no discurso das marcas. Revista Signum: Est. Linguísticos, Londrina, n.16/1, p.233-258, jun.2013.

SOARES, N. M. M. Gêneros textuais em foco- argumentação em textos opinativos. Curitiba: Appris. 2016.

SOUZA, E. M. F.; VIANA, L. D. C. O livro didático como gênero do discurso complexo. In: Anais do SILEL, v.2, n.2, Uberlândia, EDUFU, 2011.

VAN DIJK, T. Discurso e poder. FALCONE, K. (trad.). São Paulo: Ed. Contexto, 2008.

Recebido em agosto de 2019.

Aprovado em janeiro de 2020. 